\title{
Desafios presentes nos livros didáticos de história: narrar o que ainda está acontecendo ${ }^{1}$
}

Challenges Present in History Textbooks: Telling what is Still Happening

Helenice Rocha*,

\section{Resumo}

$\mathrm{O}$ artigo apresenta o resultado de um estudo exploratório em livros didáticos de História, em especial o conjunto de livros do Projeto "Narrativas nos Livros Didáticos de História: Tradição e Rupturas”, sobre o tema da "Nova Ordem Mundial." Realizamos uma análise comparativa entre 15 livros do PNLD 2011, visando produzir uma narrativa síntese, destacar recorrências e singularidades conceituais, além das interrelações entre as noções apresentadas nas narrativas principais dos livros. Trabalhamos com a hipótese que, sendo novo e desafiante nos livros, o tema apresenta uma necessária plasticidade curricular que mobiliza os autores, sua erudição e subjetividade, na produção da história imediata e exige o diálogo bibliográfico com os pares.

Palavras-chave: ensino de história; livro didático; narrativa.

\section{Abstract}

The article presents the result of an exploratory study in History textbooks, especially the set of books of the "Narrativas nos Livros Didáticos de História: Tradição e Rupturas" Project on the theme of the "New World Order". We conducted a comparative analysis among 15 books of PNLD 2011, aiming to produce a synthesis narrative, highlighting recurrences and conceptual singularities, and the interrelations between the notions presented in the main narratives of the books. We work with the hypothesis that the theme, being a new and challenging subject in the books, presents a necessary curricular plasticity that mobilizes the authors, their erudition and subjectivity for their production on immediate History, and demands the bibliographic dialogue with the pairs.

Keywords: History teaching; textbook; narrative.

A atualização é um requisito para os livros didáticos de História. Eles devem tratar dos processos e acontecimentos até os dias de hoje, mesmo que ainda es-

\footnotetext{
* Universidade do Estado do Rio de Janeiro (UERJ), Departamento de Ciências Humanas, Rio de Janeiro, RJ, Brasil. helarocha@gmail.com
} 
tejam em seu decurso. Por conta dessa exigência, podemos afirmar que a história imediata, ou a história no calor da hora, se realiza rotineiramente na produção dessas narrativas. Com o passar do tempo, os processos históricos se desenrolam e oferecem novos panoramas sobre seu desenvolvimento. Em favor de seu aperfeiçoamento, os autores podem reescrever tal narrativa, pois os livros costumam receber novas edições a cada ano ou em breves intervalos.

Acreditamos que os autores desses livros têm diante de si um grande desafio e realizam, em relação aos temas da história imediata, um trabalho de pesquisa e de síntese bastante intenso. O resultado é um texto que será continuamente reformulado até se estabilizar em uma forma canônica, em rápido diálogo com uma bibliografia específica e das ciências humanas, além da conexão necessária com os próprios acontecimentos do mundo contemporâneo. Os autores elegem caminhos relativamente singulares de abordagem sobre os temas, tópicos para o seu desenvolvimento que configuram inteligibilidade, formas de desenvolver a narrativa com princípio, meio e fim. Essa hipótese de uma necessária plasticidade dos novos temas que mobiliza os autores, sua erudição e subjetividade e o diálogo com pares - será testada neste artigo em relação ao tema da "Nova Ordem Mundial", presente nos livros didáticos do PNLD 2011 e em alguns outros, configurando 20 anos de produção editorial sobre o tema, entre 1995 e 2015, aproximadamente.

Em texto anterior sobre a ditadura militar no Brasil, que ainda é um tema recente, observamos que as coleções tratavam o tema inicialmente com uma narrativa bastante marcada por uma memória social a partir de fontes jornalísticas ou produzidas para o grande público. Havia a incorporação gradual das referências produzidas no campo das ciências humanas - especialmente sociologia e ciência política, sucedida posteriormente - em anos e décadas - pela produção historiográfica sobre o tema. Hoje o tratamento didático do tema registra divergências existentes no campo historiográfico para um tema socialmente sensível, o que evidencia seu diálogo com o campo.

Isso sugere que, para os temas ainda candentes - por serem sensíveis a memórias sociais diversas em lutas, envolverem posicionamentos diferenciados entre historiadores ou por ainda não estarem estabelecidos na produção da comunidade historiadora -, o problema dos livros seja a ausência de história escrita como fonte ou de sua convergência sobre tais temas e, não, a atualização das obras didáticas. Com base nessa constatação, supomos que temas 
contemporâneos, relacionados à atualidade no mundo e no Brasil, requisitem ainda mais o investimento dos seus autores na elaboração original de sínteses considerando-se diferentes aspectos e desafios de sua escrita.

Para enfrentar essa hipótese, fizemos este novo exercício de pesquisa exploratória, tendo como ponto de observação o tema da "Nova Ordem Mundial" com centralidade nos livros didáticos de História do Ensino Fundamental, avaliados no PNLD 2011. ${ }^{3}$ Realizamos uma análise comparativa entre as narrativas em um eixo sincrônico entre as 15 coleções, como também analisamos a narrativa de alguns livros produzidos em torno de 15 anos antes e 6 anos depois, em um eixo diacrônico, visando compreender as permanências e mudanças da narrativa sobre o tema ao longo de 20 anos. Conhecer como o tema foi elaborado e reelaborado em forma narrativa permite compreender a apropriação realizada em cada obra, a cada tempo.

Voltando ao PNLD 2011, no projeto de pesquisa "Narrativa Histórica", que se desdobra neste momento em sua segunda fase, nos propusemos a mapear os temas relativos a conteúdos curriculares da tradição, ou canônicos, presentes em 15 coleções de História que visavam atender à escola pública brasileira (no total de 16 coleções) naquele momento. Como sabemos, cada coleção é composta de quatro volumes, destinados aos anos finais do ensino fundamental. Assim, trabalhamos com 60 volumes no total. O trabalho do projeto com esse conjunto tem como finalidade perceber o movimento entre a tradição curricular em história e sua ruptura, a partir das narrativas presentes nos textos principais dos livros didáticos, sobre cada tema analisado e sintetizado.

A análise se faz na comparação entre elementos das narrativas desse conjunto de coleções, relativos a cada tema presente em ao menos 12 das 15 coleções. Fatores detonadores, sujeitos, sequências narrativas que constroem princípio, meio e fim no tratamento de cada tema, conceitos e outros elementos, o que permite conhecer as recorrências que reiteram a tradição ou singularidades que expressam rupturas em um conjunto representativo de coleções.

Entre os temas selecionados para a segunda fase do projeto está a "Nova Ordem Mundial”, no último volume da coleção, relativo à oitava série ou nono ano, descortinando o mundo atual e seus problemas. Dentro do capítulo surgem os temas da globalização, desequilíbrios de diferentes ordens, avanços tecnológicos. Habitualmente esse capítulo ou unidade apresenta um 
panorama, tal como um almanaque, com tópicos diversos. Que escolhas fazem os autores para falar sobre nosso mundo? Será uma narrativa histórica? Ou uma análise econômica, geográfica ou política? O que está escrito para ser lido e interpretado pelos alunos do nono ano fundamental, na finalização dessa suposta narrativa? E que mensagem potencial sobre o mundo contemporâneo deixam a esses alunos, como jovens na faixa dos 15 anos, habitantes dessa nave paradoxalmente globalizada, chamada planeta Terra?

Com essas indagações, evidenciamos a segunda finalidade do projeto e deste artigo: inferir os efeitos de sentido do texto, ou os sentidos potenciais presentes nas narrativas. Utilizando referenciais diversos do campo da linguagem, podemos afirmar, a priori, que o sentido não está lá, no texto, e sim no complexo processo que envolve a materialidade linguística desse texto, seu autor e seus leitores. No caso da narrativa com finalidades didáticas, há sempre a considerar a mediação realizada pelo professor, que surge como um leitor específico, estabelecendo os limites pretendidos da leitura dos alunos.

Trabalhamos com o pressuposto de que o sentido de um texto (qualquer texto) é criado no jogo interno de dependências estruturais e nas relações com o que está fora dele (Ricoeur apud Fiorin, 1997). No caso do projeto "Narrativa Histórica", compreendemos que os sentidos da narrativa histórica se constituem por mecanismos internos, textuais, e externos a ela própria. Entre os fatores internos estão as escolhas lexicais, a textualidade, a busca de clareza e de coerência global do texto. Entre os fatores externos destacamos o que acontece no mundo humano como objeto de experiência, e a escrita e a leitura como (re)construções subjetivas desse passado, além das mediações realizadas pelos professores. ${ }^{4}$

De acordo com Antoine Prost ao analisar a escrita da história, a criação de enredo é o ato fundador pelo qual o historiador "recorta um objeto particular na ilimitada trama dos acontecimentos da história", incidindo sobre a definição dos atores e dos episódios (Prost, 2008, p. 219). O enredo surge aqui como elemento de ligação que confere sentido, estabelecendo a relação do acontecimento isolado no interior de uma história narrada como um todo. Para isso, serve como ponto de encontro entre fatores díspares (agentes, fins, meios, interações, circunstâncias, acasos) e produz uma síntese do heterogêneo. Essa síntese do heterogêneo, ao incorporar o fator tempo, confere densidade ou profundidade à narrativa. 
Entendendo que toda narrativa (ficcional ou não) tem princípio, meio e fim, que possui um enredo; que na coleção de história a narrativa sobre um tema se encadeia a outra, o que contribui para a constituição de sentidos relacionados em sua sequência, organizamos o Sistema "Narrativa Histórica" - um banco de dados virtual produzido especialmente para o projeto de pesquisa - com a busca desses elementos nas narrativas (fatores desencadeadores, sujeitos e conceitos, síntese histórica). Os capítulos relacionados a 47 temas eleitos para a pesquisa se subdividem em tópicos e subtópicos, também considerados no sistema. Os relatórios do sistema permitem procurar temas, sujeitos e conceitos, e fazer comparações entre eles ou entre coleções, percebendo quando um conceito, por exemplo, foi tratado pela primeira vez em uma coleção. Permitem, também, encontrar a recorrência de um sujeito entre coleções.

Esse sistema é o ponto de partida para uma análise que pretende trabalhar com as tendências no tratamento de cada tema. Ou seja, o objetivo do projeto não é o de dar destaque a cada coleção ou livro, nem aos seus autores. Consideramos que são obras contemporâneas; algumas coleções já foram aprovadas em diversas edições do PNLD e outras são mais recentes, evidenciando um mercado em movimento e uma narrativa canônica, já estabelecida como conteúdo escolar (Rocha et al., 2017).

Trabalhar com o conjunto de livros aprovados oferece-nos a possibilidade de tratá-los como um corpus documental, e observar suas recorrências e singularidades passa a oferecer indícios potentes para uma análise curricular. Especialmente nas circunstâncias em que o tema da "Nova Ordem Mundial", em análise, se mostra um tema em construção em 2011, ainda não "canonizado", teremos a oportunidade de conhecer especificidades da construção do texto do capítulo, no que se refere às escolhas conceituais que dão suporte para a construção de sentidos dos temas em seu desenvolvimento, recorrências e não recorrências.

\section{O que é apresentado como “Nova Ordem Mundial”?}

O que se constitui nas coleções do PNLD 2011 como último capítulo ou unidade do livro do nono ano ou oitava série varia em suas denominações, entre "Nova ordem mundial", "Mundo contemporâneo" e "Nova ordem internacional", referido à atualidade do final do século XX e início do século XXI. Algumas 
coleções incluem o Brasil contemporâneo nesse mesmo capítulo ou unidade, por sua característica de obra integrada, muitas vezes após o capítulo dedicado à Nova Ordem Mundial. Para fins desta análise, fizemos o mesmo recorte realizado por parte das coleções, excluindo o Brasil e apresentando o panorama do mundo contemporâneo no que se refere a essa ordem internacional globalizada, denominada predominantemente de "Nova Ordem Mundial".

O tema é composto de diferentes subtemas ou questões, em um panorama ainda nebuloso. A partir do estopim político e econômico - com o fim da Guerra Fria e da bipolarização entre Estados Unidos da América e União Soviética -, novos polos políticos e econômicos surgem no mundo, propiciando a globalização em diferentes aspectos. Algumas coleções apontam a existência de um mundo unipolarizado, com o papel exercido pelos Estados Unidos, com a hegemonia do capitalismo. Associados a essa unipolarização, surgem os blocos econômicos, apresentados de forma diferenciada nas coleções. O desenvolvimento tecnológico, abordado de forma mais ou menos historicizada, propicia o movimento de globalização, com o aumento da rapidez na comunicação a distância e no transporte de pessoas e mercadorias.

Uma parte das coleções trata esses temas (política, economia e tecnologia) sem articulá-los, o que pode dificultar a compreensão dos alunos sobre suas inter-relações. Em alguns livros essa nova ordem está associada apenas aos aspectos econômicos e comerciais. Em outros, confere-se destaque ao desenvolvimento tecnológico sem explicar de onde vem tal desenvolvimento. Poucas coleções abordam, no leque de questões apresentadas nesse capítulo ou unidade, a questão ambiental, mas, quando o fazem, denunciam o aumento da poluição e o aquecimento global entre os problemas desse cenário.

Assim, é possível dizer que, quando a primeira década do século XXI está terminando, as coleções aprovadas no PNLD apresentam o mundo contemporâneo com algumas recorrências: a relação entre o fim da Guerra Fria, a recomposição de blocos econômicos e a globalização. Os tópicos em que se divide a globalização é que variam, bem como as ênfases na composição do panorama mundial que se desencadeia a partir dessa nova ordem. Entendemos que tais ênfases conferem, na maioria das coleções, um tom apreciativo mais ou menos positivo sobre a denominação "Nova Ordem Mundial”. Vejamos aspectos da composição dessa narrativa ou texto. 


\section{O DESENVOLVIMENTO DA NARRATIVA}

Em uma narrativa, parte da ligação de um novo tema a um tema anterior decorre da sua relação com fatores que propiciam seu acontecimento, tornando-o factível ou verossímil. Não necessariamente causas em sua conotação forte, mas fatores que propiciam ou explicam o surgimento de novos acontecimentos ou processos. Por conta disso, levando em conta que os fatores detonadores funcionam como elemento de ligação entre os capítulos que organizam os temas em uma coleção de livros de História, a ideia de fator detonador, ou de estopim, no Projeto "Narrativa Histórica" é um dos elementos buscados em relação a todos os temas pesquisados. Às vezes eles são apresentados na narrativa do próprio capítulo, de forma explícita. Às vezes, estão na finalização de capítulos anteriores, estabelecendo o "gancho" estruturante da narrativa para o início do outro.

O fator detonador para a Ordem Mundial, apontado pela ampla maioria das coleções, surge com o fim da Guerra Fria, propiciando o desequilíbrio entre blocos hegemônicos, o que parece propiciar ou ocorrer de forma paralela à globalização, segundo a narrativa das coleções em sua apresentação panorâmica de elementos. Uma parte das coleções inclui essa informação no capítulo ou unidade que vai tratar do mundo atual. Outras tratam do fim da Guerra Fria no próprio capítulo dedicado a esse tema, em unidades ou capítulos anteriores. Nesse caso, inicia-se o capítulo do mundo atual fazendo-se remissão ao fim da Guerra Fria como um fator de reequilíbrio de forças econômicas e políticas no mundo, com o fim da União Soviética e o fortalecimento dos Estados Unidos e dos blocos econômicos relacionados a esse país. Além da ênfase nesse fator desencadeador, há coleções que relacionam a Nova Ordem Mundial a eventos anteriores, como a Conferência de Bretton Woods, explicando alterações na relação entre o dólar americano e as reservas em ouro pelos países signatários da conferência, já na década de 1970 .

Seja como curiosidade ou como origem histórica, algumas coleções remetem a origem da ideia de globalização ao momento das Grandes Navegações, demonstrando que a expansão marítima europeia levou à formação de um mercado mundial que se estendeu por todos os continentes do globo, já no século XVI. A globalização contemporânea seria então uma segunda integração em escala mundial. O livro História temática apresenta esse fenômeno 
anterior como mundialização, diferenciando-o da globalização contemporânea. A narrativa do livro Vontade de saber é a única que fala sobre a Nova Ordem Mundial relacionando-a a uma possível terceira revolução industrial, remetendo ao potencial tecnológico de integração - presencial e a distância - dessa revolução.

A atribuição de um fator detonador - fim da Guerra Fria com início da globalização - e essas três remissões (Bretton Woods, terceira revolução industrial e Grandes Navegações) como expressão histórica do fenômeno da globalização representam buscas de historicização e didatização de um tema que, por sua contemporaneidade, ainda não tem o que poderíamos denominar de "profundidade temporal" - ou seja, princípio, meio e fim. Tal encadeamento de processos ao longo da história ocidental é bastante conhecido no currículo escolar. O tratamento discursivo do momento atual, denominado nas coleções do PNLD de 2011 como "Nova ordem mundial", no que se refere aos seus desdobramentos ainda carece dessa profundidade, até mesmo por estar em acontecimento.

Na coleção "História, da Primeira Grande Guerra Mundial ao início do século XXI" essa característica é apresentada pelo próprio livro, explicitamente, após o texto arrolar os temas eleitos pela obra para compor o capítulo denominado "Iniciando o século XXI. Que Nova ordem é essa?":

Cada um deles [os temas] será analisado a seguir, de forma descritiva e panorâmica, sem qualquer pretensão de esgotar o assunto, nem propor soluções para questões tão complexas e abrangentes. A ideia é propor um debate sobre os temas.

A característica assumida por essa coleção está - com mais ou menos clareza - em todas as outras, que enfrentam a construção do texto de formas diversas, mas sempre no formato "descritivo e panorâmico".

Conforme afirma Jean Lacouture (2005, p. 301) ao ignorar a conclusão do que ele narra, o historiador "imediato" constrói relações tendo que fazer mais escolhas com base em sua subjetividade. Ele não tem clareza sobre as relações causais, as relações entre fatores e os efeitos para a produção de uma narrativa. Como o livro didático habitualmente ganha edições posteriores, nesse momento o autor estabelece algumas relações parciais e apresenta descrições e aspectos isolados, que poderão se organizar de forma mais orgânica nas futuras reedições. 


\section{OS TEMAS DENTRO DO TEMA: QUE HISTÓRIA CONTA o CApÍtulo DA Nova Ordem Mundial No PNLD 2011?}

A síntese possível para o tema, a partir do conjunto de livros que dele tratam, considerando-se as variações existentes entre as coleções e a organização de unidades e capítulos, é que após o fim da Guerra Fria, caracterizado pela dissolução da União Soviética, estabelecem-se novos polos de poder político e econômico mundial, sob a liderança dos Estados Unidos da América e novos blocos regionais. $\mathrm{O}$ aumento acentuado do comércio internacional de empresas multinacionais que se tornam mundiais, o avanço tecnológico que propicia o aumento da rapidez nos meios de comunicação e de transporte de mercadorias e de pessoas viabiliza o processo denominado de globalização, mencionado na ampla maioria das coleções.

A globalização é um conceito explicado e exemplificado concretamente, sobretudo no que se refere à presença de empresas de origem norte-americana em diferentes partes do planeta. Algumas coleções qualificam a globalização em econômica e cultural. Outras apontam vantagens e desvantagens desse processo, mas isso ocorre em menor número de coleções. Algumas coleções conferem destaque ainda ao conceito de neoliberalismo, em suporte ao de globalização. Assim, em termos didáticos, nessas coleções a globalização seria um suporte explicativo para a Nova ordem, e o neoliberalismo seria um suporte para a globalização.

Entre os problemas apontados na contemporaneidade, entendida como nova ordem internacional globalizada, estão a questão ambiental e o aumento da desigualdade, este relacionado ao desemprego, em algumas coleções. Alguns livros ainda apontam como uma questão a homogeneização cultural decorrente da globalização dos mercados para os produtos das indústrias mundiais. A desigualdade ganha centralidade em algumas coleções. Tanto que, como estratégia discursiva, em algumas há até mesmo uma inversão da estrutura do texto, que começa tratando da desigualdade do mundo atual e procura explicá-la à luz do fenômeno da globalização e de todos os processos subjacentes da ordem capitalista contemporânea. Mais de uma vez, pela força das imagens de fome e miséria, usa-se a África como o caso exemplar do grande contraste entre países e continentes desenvolvidos e não desenvolvidos. Sabemos que outros fatores contribuem para esse contraste - inclusive dentro dos países -, 
mas no processo de didatização de processos complexos essa é uma recorrência relevante e que atua para conferir um acento apreciativo negativo aos efeitos da globalização no mundo contemporâneo. Se, por um lado, esse uso é eficaz no sentido de provocar a crítica social, por outro, sabemos que pode reiterar imagens acerca de um continente que também apresenta diversidade social.

Essa estratégia de construção do texto com casos de países, continentes ou regiões geográficas é utilizada em outros casos, o que evidencia também o diálogo dos autores com as referências da geografia. Se, por um lado, em todas as coleções se menciona a União Soviética pelo seu declínio e os Estados Unidos da América pelo grande predomínio que passa a exercer após o fim da Guerra Fria, por outro, menciona-se a China como novo polo econômico, ou o Japão após o fim da Segunda Guerra Mundial.

Os blocos econômicos, que surgem ou se fortalecem, também ocupam esse lugar, como a Europa e a Comunidade Comum Europeia e o Mercosul. Em alguns casos essas regiões ou blocos ganham o status de sujeitos históricos, pois são apresentados como realizando ações e lutando pela supremacia econômica e política diante de outros sujeitos. Essa é uma das oportunidades em que se desenvolve, mesmo que de forma incipiente, o que podemos denominar uma narrativa histórica - no sentido atribuído por Ricoeur - com o breve desenvolvimento de uma intriga (Prost, 2008, p. 219). Mas tal narrativa nem está presente em todas as coleções, nem estabelece ligações com outras seções além daquela a que se refere.

Assim, no âmbito da produção de sentidos, é possível concluir que os textos sobre a "Nova Ordem Mundial" se apresentam, de forma geral, descritiva e não analiticamente nos livros do PNLD 2011, o que pode criar dificuldades para a produção de inter-relações causais e temporais entre os tópicos que são apresentados na sequência: desenvolvimento tecnológico, desigualdade regional e entre países, problemas ambientais. Parece que o desconhecimento dos efeitos do que denominam como Nova Ordem Mundial e globalização dificulta aos autores desses textos o estabelecimento de relações claras entre as estruturas e os eventos, os processos e os acontecimentos.

\section{A TRAJETÓRIA DE INTERLOCUÇÕES}

Utilizando hipótese semelhante à que desenvolvemos em artigo anterior sobre a ditadura militar no Brasil, compreendemos que, para elaborar um texto 
didático sobre um tema novo, ou acerca de um processo que ainda está em curso, os autores possivelmente não encontrarão ainda referências historiográficas em quantidade. No que se refere ao tema da Nova Ordem Mundial, fizemos um levantamento em cada livro, a partir de termos de busca.

Utilizamos inicialmente como referência de pesquisa na bibliografia mencionada "globalização", "nova ordem mundial ou internacional", "século XX" ou expressões do mesmo campo semântico. A seguir percebemos que a referência à globalização ocorria, mas à "nova ordem", não. Os autores mencionam livros sobre o século XX ou XXI.

Vejamos as recorrências de citação. Quinze obras citam em suas bibliografias o livro A Era dos Extremos, de Eric Hobsbawm, com edições entre 1995 e 2005. A segunda obra mais citada é o livro de Nicolau Sevcenko Na corrida para o século XXI, com sete citações, a partir de 2003. O livro de Mark Mazower, Continente sombrio - a Europa no século XX, lançado em 2001, é o terceiro mais citado. Vemos que são obras de historiadores, que fazem uma reflexão sobre o século XX, de onde os autores recolhem elementos para pensar o momento em que ocorre o processo de globalização, já no final do século XX e início do XXI.

Depois desses, há um número variável de três a quatro citações a obras de sociólogos e geógrafos, além de um historiador. São obras de Octavio Ianni, Milton Santos, Daniel Aarão Reis Filho e outros, como Demetrio Magnoli e Emir Sader, tematizando especialmente a globalização. Vale dizer que as obras sobre o tema surgem entre 1998 e 2003. Finalmente, há obras citadas uma única vez em alguns livros, relativas à geografia, à sociologia ou à política internacional.

O menor número de obras citadas na bibliografia dos livros com essas palavras de busca foi de dois livros, e o maior foi de oito, perfazendo a média de cinco livros por coleção, relativamente ao tema da nova ordem mundial e globalização. Ou seja, o tema é objeto de pesquisa em todas as coleções, considerando o aspecto histórico da globalização, mas também outros, como o sociológico, o político e o econômico. As obras citadas são voltadas para o público em geral e acadêmico, e a bibliografia é necessariamente recente (dos 12 anos anteriores em relação ao livro didático).

Essa média de referências e sua variedade evidenciam um trabalho de pesquisa relevante por parte dos autores, levando-se em conta que é um tema ainda em construção. Dessas obras, metade fornece predominantemente 
elementos para a elaboração de retratos ou descrições possíveis do mundo atual, sendo produções da sociologia, geografia ou da ciência política. A outra metade é composta por obras de história.

Em comparação com os livros das coleções que permanecem no PNLD 2017 e que tratam do mesmo tema, há algumas alterações. Entre as seis coleções que permanecem, na maioria são conservadas as mesmas referências bibliográficas do PNLD 2011. Em duas, acrescentam-se algumas referências, e em três delas são retiradas referências que não eram predominantes entre as citadas anteriormente. Ou seja, as referências mais recorrentes permaneceram em todos os livros. E entram mais algumas poucas, variadas entre os livros.

Essa característica sugere que os textos principais permaneceriam os mesmos, ou muito próximos. Será que é isso o que ocorreu? Para responder a essa pergunta, comparamos as narrativas de livros do PNLD 2011 e do PNLD 2017 das seis coleções que permaneceram entre um e outro edital. Para explicitar as relações entre as obras que passaremos a comparar, vejamos as alterações de títulos entre um e outro edital:

Quadro 1 - Alterações das obras entre PNLD 2011 e PNLD 2017

\begin{tabular}{|c|c|c|}
\hline Autores & Coleção no PNLD 2011 & Coleção no PNLD 2017 \\
\hline Cláudio Vicentino & Projeto "Radix" & Projeto Mosaico \\
\hline $\begin{array}{c}\text { Claudio Vicentino } \\
\text { José Bruno Vicentino }\end{array}$ & & $\begin{array}{c}\text { História, Sociedade e } \\
\text { Cidadania }\end{array}$ \\
\hline Alfredo Boulos Júnior & $\begin{array}{c}\text { História, Sociedade e } \\
\text { Cidadania }\end{array}$ & Historiar \\
\hline $\begin{array}{c}\text { Gilberto Cotrim } \\
\text { Jaime Rodrigues }\end{array}$ & Saber e Fazer História & Araribá \\
\hline $\begin{array}{c}\text { Maria Raquel Apolinário (ed.) } \\
\text { Obra coletiva Editora Moderna }\end{array}$ & Araribá & Vontade de Saber História \\
\hline $\begin{array}{c}\text { Marco César Pellegrini } \\
\text { Adriana Machado Dias } \\
\text { Keila Grinberg }\end{array}$ & Vontade de Saber História & Estudar história: das Origens \\
do Homem à Era Digital
\end{tabular}

Fonte: elaborado pela autora, com base nas obras consultadas. 


\section{Percurso temporal da narrativa "Nova Ordem Mundial"}

A expansão da narrativa em sua materialidade do texto é uma tendência entre as obras que foram aprovadas entre um e outro PNLD. O livro História, Sociedade \& Cidadania é a obra que apresenta a maior expansão no tratamento da temática. Na narrativa de 2011 dedicava 11 páginas ao tema e, na de 2017, 25 páginas. Além da coleção mencionada, a "História: das Cavernas ao terceiro milênio", que muda de nome para "Estudar história: das Origens do Homem à Era Digital”, passou de 7 para 16 páginas; a coleção “Araribá”, de 5 para 12 páginas, e a coleção "Vontade de Saber", que antes dedicava 6 páginas ao tema, passou para 8 páginas, tendo agora um outro capítulo de 6 páginas para o tema das guerras que eclodiram no mundo nas últimas décadas e problemas do mundo atual, relacionados à Nova Ordem Mundial, somando 14 páginas (em outras coleções esse tema é tratado dentro da temática da Nova Ordem). Das outras duas coleções trataremos adiante, para buscar compreender o porquê de fugirem à tendência de expansão da narrativa.

Voltando à expansão da narrativa na coleção "História, Sociedade \& Cidadania", o livro de 2011 iniciava a narrativa com o título "A nova ordem internacional", enquanto no livro de 2017 o altera para "Nova ordem mundial". Em ambos, faz-se a abertura enfatizando os aspectos tecnológicos e culturais da globalização, com jovens que poderiam ser de qualquer parte do mundo. O livro de 2017 incorpora às transformações tecnológicas ocorridas nas últimas décadas do século XX a denominação de Terceira Revolução Industrial, como o conjunto de inovações ocorridas nos anos 1970 e que teriam contribuído para o processo de globalização. Em ambos os livros a coleção trata das características da globalização e do neoliberalismo, que se estabelecem como tópicos canônicos do conteúdo. Também continua enfatizando a circulação de informações e a formação de blocos econômicos.

A coleção de 2017 acrescenta o tópico, já presente em outras coleções em 2011, relativo ao desemprego na globalização, bem como registra a existência de protestos contra a globalização, através do Fórum Social Mundial. Por último, conferindo um tom negativo ao momento da nova ordem, trata de conflitos e tensões no mundo atual e finaliza o capítulo com uma lista de seis desafios que a humanidade enfrenta no presente e daqui para frente, ou seja, em seu futuro. 
É interessante observar que a noção ou conceito de terceira revolução industrial estava presente em apenas uma coleção (entre 16) no PNLD de 2011 - a "Vontade de Saber" -, e se expandiu para seis no PNLD de 2017. Também a correlação entre globalização e desemprego, feita em algumas coleções e em 2017 generalizada, contribui para evidenciar que os autores dos livros didáticos realizam a função de mediadores sociais do conhecimento, não apenas reproduzindo os conteúdos já estabelecidos, mas constituindo outros, ao estabelecer relações e explicar fenômenos com o apelo a categorias explicativas, por ser necessário falar da atualidade quando ainda não há bibliografia disponível.

Consideramos que, para além da bibliografia especializada, as próprias coleções possam ser fontes para as demais, na busca do que é importante tratar, ao considerar um tema novo como esse. Se assim for, existiria um efeito de "invenção da tradição" curricular em cadeia ou do estabelecimento de tópicos ícones, também nos conteúdos considerados novos em História, a partir da eficácia de termos ou conceitos para explicar fenômenos ou processos em curso. Parece-nos que é isso que vem se passando com a noção de terceira revolução industrial como suporte à ideia de globalização em seu aspecto tecnológico e cultural. Essa noção já era presente nos livros de História quando do tratamento do tema Revolução Industrial, que em algumas coleções recebe uma periodização. Mas aqui o conceito é mobilizado operacionalmente para explicar a globalização, o que é diferente de ser explicado como um momento da revolução industrial. Ou seja, os autores precisam constituir uma explicação que articule os eventos ou processos com categorias explicativas que os organizem (Fiorin, 1997, p. 20).

Em 2012 foi lançado no Brasil o livro A Terceira Revolução Industrial, do economista Jeremy Rifkin, provocando uma repercussão social em torno de uma noção, até então, menos importante para além da escola e dos meios acadêmicos. Conforme proposto por André Chervel em seu clássico texto sobre a criação das disciplinas escolares, pode-se afirmar que essa é uma noção que ganha importância social, para além de escolar (Chervel, 1990).

Outra demonstração de que os autores, em relação a um tema novo, estão ainda consolidando a narrativa e seus pontos centrais, está na escolha de Cotrim e Rodrigues, no PNLD 2011, ao enfatizar logo no início do capítulo a desigualdade para abordar a Nova Ordem Mundial, desenvolvida em 20 
páginas. Também era uma noção desenvolvida por outras três obras do PNLD 2011 e que se expande em 2017, tal como a noção de terceira revolução industrial.

Entretanto, no livro de Cotrim do PNLD 2017 esse capítulo é reduzido, de 20 para 12 páginas, e o próprio volume da obra cai de 304 para 271 páginas. O tema da desigualdade e as críticas aos efeitos perversos da globalização são muito resumidos, reconfigurando a narrativa. Certamente optou-se por reduzir o escopo de temáticas tratadas no capítulo, no que a crítica a tais efeitos foi considerada menos importante. O efeito de sentido dessa condensação, no tratamento do tema, é que ele se torna mais conceitual, oferecendo a definição de globalização e neoliberalismo, por exemplo, e mais "neutro", ou menos crítico, ao não se referir aos efeitos deletérios da globalização. Vemos que decisões editoriais também afetam a extensão dos textos e, portanto, o investimento no desenvolvimento de um novo tema e seus desafios.

Ampliemos um pouco mais a temporalidade no exame do percurso de obras de um mesmo autor. Consideremos a obra História integrada, da oitava série do ano de 1995, de autoria de Claudio Vicentino, o mesmo autor da obra Radix do PNLD 2011 e um dos autores de Mosaico, do PNLD 2017. No livro de 1995, na Unidade III, "O mundo atual”, apresenta no último capítulo o título "A crise do bloco capitalista e a Nova Ordem Mundial". Ou seja, a Nova Ordem ainda não se constituía um tópico a ser discriminado como capítulo.

Predomina no capítulo de 1995 o que irá se denominar posteriormente como Fim da Guerra Fria, e que na obra do mesmo autor, já em 2011, está em um capítulo anterior, à parte, como "O fim do bloco soviético". O item "A nova ordem internacional" consta de duas páginas, em que se aborda a formação de blocos econômicos e o aumento da desigualdade mundial, com transformações nos países socialistas remanescentes. Ou seja, os tópicos do tema recebem tratamento sumário, sem referência à globalização e sem referências bibliográficas.

Esse era um tema muito recente no início da década de 1990. As referências acadêmicas sobre o tema de uma nova ordem mundial começam a surgir com efetividade a partir de meados da década. Claudio Vicentino produziu um suplemento que visava atualizar obras didáticas, denominado "Nova ordem internacional: Cenário Mundial” (Vicentino; Scalzaretto, 1992). Os autores, na introdução, procuram estabelecer uma interlocução crítica com a ideia de Nova Ordem Internacional e justificam o sentido de seu suplemento pela 
necessidade de esclarecimento do público, já que houve uma primeira recepção até entusiasmada ao fim do socialismo, no que eles demonstram desconfiança. Concluímos que, na obra de 1995, a inclusão do tema da Nova Ordem atende à prescrição de atualização, utilizando suas próprias referências e obras que tratam das crises do próprio século XX, assumindo uma posição crítica a seus aspectos negativos.

No livro do PNLD 2011, Radix, observa-se a expansão do tema da nova ordem, que ganha um capítulo inteiro com 11 páginas, um tratamento mais conceitual à globalização, com a inclusão do neoliberalismo na narrativa e detalhamento relativamente a países da América Latina em seu desenvolvimento econômico e político nos últimos anos, incluindo Cuba, México, Chile e Argentina. Em sua seção destinada à bibliografia refere os livros já mencionados na seção "A trajetória de interlocuções", acrescentando três obras relativas à história da América Latina, coerentemente com a ênfase singular do livro na situação de outros países latino-americanos no momento da globalização.

O livro do mesmo autor, Mosaico, no PNLD 2017, demonstra bem como o trabalho de reelaboração do texto acerca da atualidade é constitutivo do texto didático de história. O ano de edição é 2015, 8 anos após o lançamento de Radix, do PNLD 2011. Mas, se lá a estrutura era a já citada, aqui temos um módulo intitulado "O fim da Guerra Fria e a Nova Ordem Mundial”, composto de dois capítulos: "O fim do bloco soviético e da Guerra Fria" e "Outra ordem mundial". O capítulo da "Outra ordem mundial”, que mantém 11 páginas, se inicia estabelecendo um link entre o mundo pós-Guerra Fria e a globalização, o neoliberalismo e as crises econômicas e sociais.

Como existe uma passagem do tempo e os efeitos da globalização já se fazem sentir mais, podemos dizer que o texto consegue adquirir certa profundidade temporal, o que antes não era possível perceber por meio da materialidade linguística. A obra apresenta guerras promovidas pelos Estados Unidos com base em sua hegemonia, além de outros efeitos mundiais do fenômeno da globalização. O detalhamento sobre a situação dos países da América Latina é condensado no item "Neoliberalismo na América Latina", mas a ideia de crise decorrente dessa outra ordem é enfatizada, tanto na América Latina quanto no resto do mundo. 
Como obra integrada, após um capítulo sobre o Brasil na globalização, o livro apresenta um capítulo final denominado "O nosso tempo". Na abertura do capítulo os autores chamam atenção dos leitores para o que pretendem denominar de história do tempo presente e para as fotografias que representam a atualidade: jovens sentados no espaço público, entretidos com seus celulares. As legendas identificam esses jovens em cidades diversas do mundo. A temática do capítulo é a dos avanços tecnológicos e dos perigos da manipulação da informação, da produção, consumo e meio ambiente, da venda e consumo de armas e drogas. Algumas dessas escolhas são novamente singulares. Evidenciam preocupações dos autores com o futuro que se descortina, e que decidem compartilhar com os leitores como possiblidades de futuro. São alternativas escolhidas a partir da subjetividade do historiador para tratar da história imediata, como afirmado por Lacouture (2005), citado no início deste artigo.

Em síntese, na obra de Vicentino, a Nova Ordem Mundial, em 1995, finalizava a crise do bloco capitalista. No PNLD 2011 ganha um capítulo inteiro. E no PNLD 2017 organiza um módulo inteiro e se desdobra em três capítulos, tendo o Brasil na era da globalização entre os dois destinados à história mundial. Uma obra que acompanha um tema ao surgir, como é o caso das obras de Claudio Vicentino no que se refere ao tema da "Nova Ordem Mundial", que passa a ser "Outra Ordem Mundial”, nos ajuda a perceber que, em relação a temas da atualidade, os autores de livros didáticos necessitam fazer um investimento inicial com bibliografia escassa, recorrendo a sua própria erudição, organizando de forma didática informações disponíveis ao público em geral.

\section{À GUISA DE CONCLUSÃo}

Iniciamos este artigo com algumas hipóteses acerca do papel dos autores dos livros didáticos no que se refere aos temas da atualidade, que representam a escrita da história imediata, conforme a proposição de Jean Lacouture. Concluímos que, comparando a escrita sobre a Nova Ordem Mundial e a escrita sobre a Ditadura Militar no Brasil, há diferenças não apenas temporais. A Ditadura Militar, sendo um tema sensível da história do Brasil, mobilizou de forma diversa os historiadores nacionais, que também se posicionaram de forma diferenciada em relação com a memória que habita a todos, historiadores ou não. Já a Nova Ordem Mundial, como um tema em acontecimento em 
nível planetário que envolve processos de maior duração, já dispunha de referências sobre o século XX que forneciam sinais do que estava por vir. A globalização como noção de apoio à Nova Ordem Mundial, como vimos no PNLD 2011, requisitou a produção de referências que começou a ocorrer nos anos finais do século XX e se desenvolve até hoje, como história imediata, pois essa ordem vem se transmutando.

Conforme vai sendo disponibilizada bibliografia qualificada, os autores vão buscando nessas referências o mais adequado às finalidades didáticas, utilizando para isso estratégias de apropriação e de tradução que merecem ser mais estudadas. Os autores de livros didáticos acabam por se constituir, no que se refere a esses temas, elaboradores de conteúdos curriculares, ao compor a narrativa sobre o novo tema. Como vimos, eles elaboram uma explicação que articula os eventos ou processos com categorias explicativas que os organizem. É o caso exemplar da terceira revolução industrial, categoria explicativa que organiza o conjunto de tecnologias relacionadas à ampliação da comunicação e ao aumento da rapidez no deslocamento planetário, mobilizada a partir do tema da revolução industrial.

A entrada de noções e conceitos do mundo social na escola, considerando a proposição feita por André Chervel (1990) para a constituição das disciplinas escolares, ocorreria a partir da percepção de sua importância e das finalidades estabelecidas socialmente. Isso se dá por mediações como a que ocorre aqui, na escrita didatizada de material de ensino - no caso, livros didáticos de história - sobre acontecimentos ou processos que ainda estão em curso, mas se tornam objeto do currículo escolar.

Resta considerar os efeitos de sentido de um tema que aborda o nosso mundo diante de suas maravilhas tecnológicas, mas, ao mesmo tempo, de seus limites. Percebe-se em diversas obras do PNLD 2011 a preocupação com o horizonte de expectativas que o encerramento da obra delineia. Algumas obras elencam mais aspectos positivos sobre a Nova Ordem e a globalização, sem tratar de problemas. Outras procuram produzir efeitos de sentido em equilíbrio, apresentando prós e contras. E outras, ainda, carregam mais nas tintas dos aspectos deletérios da globalização e do mundo contemporâneo. Entre as obras de 2011 e as que permaneceram em 2017, percebe-se a busca de diversificação: as que antes apresentavam apenas aspectos positivos (exemplo: 
tecnologia) agora tratam também de efeitos deletérios (exemplo: degradação ambiental). E vice-versa.

Certamente, os alunos já trazem uma visão sobre o mundo e seus problemas ao tomar conhecimento, nas aulas de História, sobre o momento atual. $\mathrm{O}$ registro de uma aluna do oitavo ano, conforme registra Penna (2015), é sintomático:

Vivemos em um mundo em que todos os dias vemos a humanidade caminhar para um pior caminho. Pensar no quanto tempo ainda temos até todos nossos recursos acabarem é inevitável. Mas não podemos deixar de citar os desenvolvimentos tecnológicos. Um mundo que cresce e desenvolve-se cada vez mais e, também traz preocupações. Vivemos em total dúvida sobre o amanhã.

Segundo Penna, o mais perturbador na resposta dessa aluna não são as visões de passado, presente e futuro implícitas, mas a impossibilidade de mudança, o fatalismo explícito em virtude das desgraças vindouras. Complementamos: chama atenção a ausência de percepção de um papel para si, como sujeito histórico, na possibilidade de mudança. Percebe-se que a aluna menciona tópicos arrolados nas coleções de 2011, bem como os de 2017. Tomar conhecimento deles não modifica, em princípio, o posicionamento dos jovens diante de um cenário atual que inspira preocupação a todos.

Conhecer o panorama do mundo atual apresentado no capítulo sobre a Nova Ordem Mundial é um momento do estudo da história. Mas é preciso que os livros propiciem uma reflexão que inspire o autorreconhecimento dos alunos como sujeitos históricos, passíveis de fazer a história.

A iniciativa de produzir capítulos finais que convidam à reflexão sobre o presente em sua relação com o futuro parece ser positiva e original, pois não se respalda na história enquanto algo passado, mas como posicionamento sobre o tempo, inclusive sobre o que virá. E confirma, provisoriamente, a hipótese apresentada sobre a plasticidade das narrativas de novos temas como um território passível do novo e original. No tema relacionado a "presente e futuro", estabelece-se um lugar, em especial, de escolhas possíveis dos autores de livros didáticos, considerando o que ainda pode ser o currículo no ensino de história, em meio a pressões para ser tão somente a instrução e a informação "neutralizada", destituída de reflexão sobre o que é ético, solidário e relevante - em um mundo que se transforma veloz e brutalmente - na relação educativa entre gerações. 


\section{REFERÊNCIAS}

CHERVEL, André. História das disciplinas escolares: reflexões sobre um campo de pesquisa. Teoria \& Educação, Porto Alegre, n. 2, p. 177-229, 1990.

FIORIN, José Luiz. Teorias do discurso e ensino da leitura e da redação. Revista Gragoatá, Niterói, v. 2, n. 1, p. 7-27, 1997.

LACOUTURE, Jean. A história imediata. In: LE GOFF, Jacques; CHARTIER, Roger; REVEL, Jacques. A História Nova. Trad. Eduardo Brandão. 5. ed. São Paulo: Martins Fontes, 2005. p. 288-323.

PENNA, Fernando. A total dúvida sobre o amanhã e o desafio de ensinar História: concepções de tempo na produção textual de alunos. História \& Perspectivas, Uberlândia: UFU, v. 28, n. 53, p. 71-97, 2015.

PROST, Antoine. Doze lições sobre a história. Trad. Guilherme João de Freitas Teixeira. Belo Horizonte: Autêntica, 2008. (Coleção História e Historiografia).

ROCHA, Helenice; MAGALHAES, Marcelo; REZNIK, Luis. Livros didáticos de História: entre políticas e narrativas. Rio de Janeiro: Ed. FGV, 2017.

RIFKIN, Jeremy. A terceira Revolução Industrial. São Paulo: Martins Fontes, 2012.

ROCHA, Helenice; MAGALHAES, Marcelo; REZNIK, Luis. Livros didáticos de História: entre políticas e narrativas. Rio de Janeiro: Ed. FGV, 2017.

\section{Documentos}

APOLINÁRIO, Maria Raquel (ed.). Projeto Araribá. 3. ed. São Paulo: Moderna, 2010. APOLINÁRIO, Maria Raquel (ed.). Projeto Araribá. 4. ed. São Paulo: Moderna, 2014. BOULOS JÚNIOR, Alfredo. História, Sociedade \& Cidadania. São Paulo: FTD, 2010. BOULOS JÚNIOR, Alfredo. História, Sociedade \& Cidadania. 3. ed. São Paulo: FTD, 2015.

BRAICK, Patricia R.; MOTA, Myria B. História: das cavernas ao Terceiro Milênio. São Paulo: Moderna, 2010.

BRAICK, Patricia R.; MOTA, Myria B. Estudar História: das origens do homem à Era Digital. 2. ed. São Paulo: Moderna, 2015.

CABRINI, Conceição A.; CATELLI JUNIOR, Roberto; MONTELLATO, Andrea R. História temática. São Paulo: Scipione, 2009.

CARDOSO, Oldimar P. Tudo é História. São Paulo: Ática, 2009.

COTRIM, Gilberto; RODRIGUES, Jaime. Saber e fazer História. São Paulo: Saraiva, 2009.

COTRIM, Gilberto; RODRIGUES, Jaime. Historiar. São Paulo: Saraiva, 2015.

DOMINGUES, Joelza E. História em Documento - imagem e texto. São Paulo: FTD, 2010. 
DREGUER, Ricardo; TOLEDO, Eliete. Nova História - conceito e procedimentos. São Paulo: Atual, 2009.

FIGUEIRA, Divalte G.; Vargas, João T. Para entender História. São Paulo: Saraiva, 2009.

MELLO, Leonel Itaussu de A.; COSTA, Luis César A. História. São Paulo: Scipione, 2009.

MOTOOKA, Debora Y.; NEMI, Ana Lucia L.; BARBOSA, Muryatan; REIS, Anderson R. dos. Para viver juntos - História. São Paulo: SM, 2009.

PANAZZO, Silvia; VAZ, Maria Luisa. Navegando pela História. São Paulo: FTD, 2010.

PELLEGRINI, Marco César; DIAS, Adriana M.; GRINBERG, Keila. Vontade de saber História. São Paulo: FTD, 2009.

PELLEGRINI, Marco César; DIAS, Adriana M.; GRINBERG, Keila. Vontade de saber História. São Paulo: FTD, 2015.

PILETTI, Claudino; LEMOS, Thiago T. de. História e vida integrada. São Paulo: Ática, 2008.

VICENTINO, Claudio. História integrada. São Paulo: Scipione, 1995.

VICENTINO, Claudio. Projeto "Radix" - História. São Paulo: Scipione, 2010.

VICENTINO, Claudio; SCALZARETTO, Reinaldo. Nova ordem internacional: cenário mundial. São Paulo: Scipione, 1992.

\section{NOTAS}

${ }^{1}$ Este artigo é resultado de Projeto "Narrativas nos Livros Didáticos de História: Tradição e Rupturas", que conta com apoio PROCIENCIA (UERJ/Faperj) no período 2017-2020.

${ }^{2}$ Professora adjunta do Departamento de Ciências Humanas, Procientista UERJ, pesquisadora do Ensino de História, coordenadora do Grupo de pesquisa interinstitucional Oficinas de História.

${ }^{3}$ Agradecemos a colaboração dos bolsistas de apoio ao Projeto "Narrativas nos Livros Didáticos de História: Tradição e Rupturas" na produção dos materiais intermediários da pesquisa, que propiciam as comparações no eixo sincrônico do PNLD 2011. Em especial a Amanda Cristina Barbosa Cardozo, bolsista de iniciação científica (Faperj), e Francisca Iglesia Nascimento Sampaio, bolsista de Estágio Interno Complementar (UERJ), responsável atual pela parte operacional do projeto.

${ }^{4}$ Este trecho do texto é uma síntese de alguns pressupostos do Projeto "Narrativas nos Livros Didáticos de História: Tradição e Rupturas", que orientaram a análise presente também neste texto. Para mais informações sobre tais pressupostos, ver ROCHA et al., 2017.

Artigo recebido em 4 de novembro de 2018. Aprovado em 5 de fevereiro de 2019. 